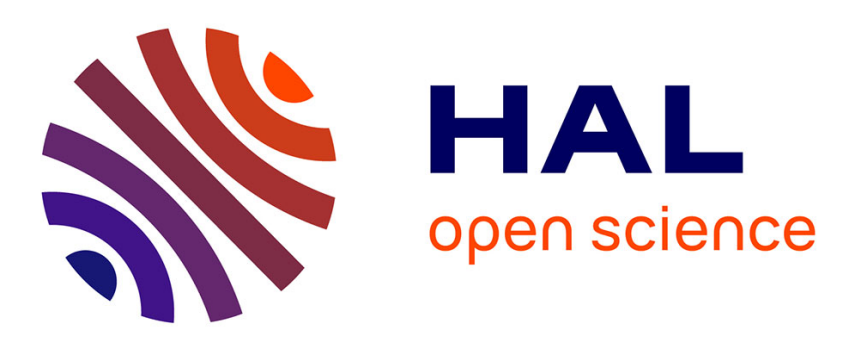

\title{
The tools of globalization. Ways of regulating and the structure of the international regime for pharmaceuticals
}

David Demortain

\section{To cite this version:}

David Demortain. The tools of globalization. Ways of regulating and the structure of the international regime for pharmaceuticals. Review of International Political Economy, 2015, 22 (6), pp.1249-1275. 10.1080/09692290.2015.1066695 . hal-01199694

\section{HAL Id: hal-01199694 \\ https://hal.science/hal-01199694}

Submitted on 15 Sep 2015

HAL is a multi-disciplinary open access archive for the deposit and dissemination of scientific research documents, whether they are published or not. The documents may come from teaching and research institutions in France or abroad, or from public or private research centers.
L'archive ouverte pluridisciplinaire HAL, est destinée au dépôt et à la diffusion de documents scientifiques de niveau recherche, publiés ou non, émanant des établissements d'enseignement et de recherche français ou étrangers, des laboratoires publics ou privés. 
This article was downloaded by: [LSE Library Services]

On: 13 August 2015, At: 00: 14

Publisher: Routledge

Informa Ltd Registered in England and Wales Registered Number: 1072954

Registered office: 5 Howick Place, London, SW1P IWG

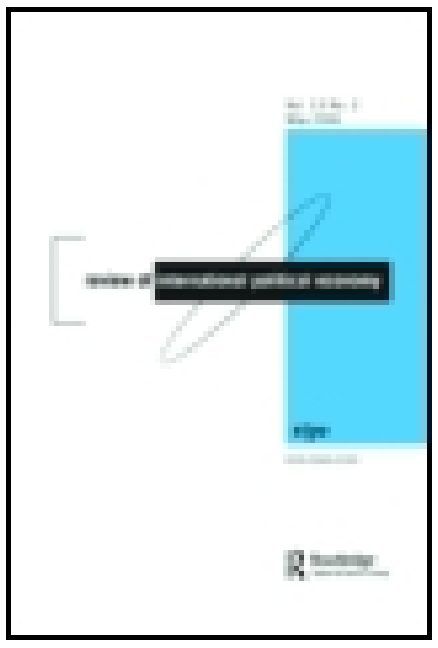

CrossMark

\section{Review of International Political Economy}

Publication details, including instructions for authors and subscription information:

http:// www. tandfonline.com/loi/ rrip20

\section{The tools of globalization: ways of regulating and the structure of the international regime for pharmaceuticals}

\author{
David Demortain $^{a}$ \\ a INRA, UMR 1326 Laboratoire Interdisciplinaire \\ Sciences Innovations Sociétés (LISIS), 77454 Marne-La- \\ Vallée, France \\ Published online: 28 J ul 2015.
}

Click for updates

To cite this article: David Demortain (2015): The tools of globalization: ways of regulating and the structure of the international regime for pharmaceuticals, Review of International Political Economy, DOI: 10.1080/ 09692290.2015.1066695

To link to this article: http:// dx. doi.org/ 10.1080/09692290.2015.1066695

\section{PLEASE SCROLL DOWN FOR ARTICLE}

Taylor \& Francis makes every effort to ensure the accuracy of all the information (the "Content") contained in the publications on our platform. However, Taylor \& Francis, our agents, and our licensors make no representations or warranties whatsoever as to the accuracy, completeness, or suitability for any purpose of the Content. Any opinions and views expressed in this publication are the opinions and views of the authors, and are not the views of or endorsed by Taylor \& Francis. The accuracy of the Content should not be relied upon and should be independently verified with primary sources of information. Taylor and Francis shall not be liable for any losses, actions, claims, proceedings, demands, costs, expenses, damages, and other liabilities whatsoever or howsoever caused arising directly or indirectly in connection with, in relation to or arising out of the use of the Content. 
This article may be used for research, teaching, and private study purposes. Any substantial or systematic reproduction, redistribution, reselling, loan, sublicensing, systematic supply, or distribution in any form to anyone is expressly forbidden. Terms $\&$ Conditions of access and use can be found at http:// www.tandfonline.com/page/terms-and-conditions 


\title{
The tools of globalization: ways of regulating and the structure of the international regime for pharmaceuticals
}

\author{
David Demortain
}

\author{
INRA, UMR 1326 Laboratoire Interdisciplinaire Sciences Innovations Sociétés \\ (LISIS), 77454 Marne-La-Vallée, France
}

\begin{abstract}
This article investigates the relationship between regulatory globalization and neoliberal standard-setting arrangements building on industry capacities and responsibilities. Focusing on international pharmacovigilance, it recounts the history of the World Health Organization programme for the international drug monitoring, to shed light and explain the concomitant rise of the International Conference on Harmonization and of its standards. It shows that the neoliberalization of a regime or installation of a regulatory standardsetting arrangement responsibilizing the industry is inseparable from the emergence of an altogether different way of regulating pharmaceuticals (including a different definition of the problem of pharmaceuticals safety, of the organizations in charge of this problem and of the kinds of expertise and information used to make decisions about it). This happens incrementally, through gradual changes and hybridization of the existing regime, much more than all-out replacement of the regime. The rise of a market-oriented regulatory arrangement can therefore not be reduced to the influence of a neoliberal scheme, but is on the contrary linked to the ways in which a tool gains legitimacy as a way of tackling a global issue.
\end{abstract}

\section{KEYWORDS}

regulation; international regime; neo-liberalism; pharmaceuticals; WHO; ICH.

\section{INTRODUCTION}

Regulatory globalization goes hand in hand with what some authors have called 'regulatory capitalism' (Levi-Faur 2005; Braithwaite 2008) or the greater involvement of private actors in regulatory arrangements. 
Transnational regulatory schemes are effectively more and more frequently inspired and run by private actors (Pattberg 2005; Vogel 2008; Mattli and Woods 2009; Abbott and Snidal 2009), testifying to the influence of neoliberal policy scripts on international regulatory regimes (Bartley 2007). This paper interrogates this relation between marketenhancing regulatory arrangements and globalization, and more specifically investigates how these arrangements gain legitimacy to generalize and inform international regimes?

The article approaches the regime for pharmaceuticals from the vantage point of the various ways of regulating that have prevailed over time, to better understand the context in which new regulatory arrangements based on greater industry responsibilization in the setting and enforcement of standards gain legitimacy globally. The international control of pharmaceutical safety, and of post-marketing safety or pharmacovigilance in particular, is an interesting case precisely because it evolved towards greater use of the tool of regulatory standard-setting.

Drug safety monitoring or pharmacovigilance ${ }^{1}$ can be operated in two ways. In a first sense, pharmacovigilance is based on systems of spontaneous notification: the systematic collection and analysis of reports signalling potential adverse effects, originating from physicians and other health professionals prescribing or administering medicines. The development of formal systems of spontaneous notification started first historically, and was international from the start. In the 1960s, several countries launched programmes of collection and analysis of reports of suspected adverse drug reactions in collaboration with the medical profession. The World Health Organization (WHO) also created the 'WHO programme for international drug monitoring' (the WHO programme hereafter) in 1968 - still operated by a collaborating centre based in Sweden, the Uppsala Monitoring Centre (UMC). ${ }^{2}$

The second method, 'active pharmacovigilance', makes use of postmarketing safety studies, most often by the industry (also called postauthorization studies or phase IV studies ${ }^{3}$ ). They are designed to analyse the adverse effects that arise in a controlled population taking a given medicine. Active pharmacovigilance is the form of drug monitoring that has been most actively promoted in the past two decades, as testified by the adoption and systematic application of European, American or international guidance applying to such studies (Demortain 2008, 2011; Davis and Abraham 2011). The guidelines are generally developed in the International Conference on Harmonization of Technical Requirements for Registration of Pharmaceuticals for Human Use (ICH). The ICH routinely produces guidelines, including for pharmacovigilance (Daemmrich 2004), according to an agreed upon procedure involving expert working groups comprised of representatives of the US Food and Drug 
Administration, the European Union and the Japanese Health ministry, industry groups, and other observers such as patient associations or the WHO. ${ }^{4}$

In this paper, I show that inherent in the globalization of regulation is a process of transformation of the actual way of regulating pharmaceuticals. Over time, pharmaceuticals safety has come to be managed by negotiating international standards to generate industry data, as much as or more than by running public and professional systems of surveillance. This is inseparable from a set of other changes that occurred in various sites and scales, namely in the way the problem of pharmaceutical safety is framed, in the conception of knowledge that is appropriate for regulatory control, as well as in the kind of public organizations shouldering pharmaceutical control and their audiences. This leads to a three-fold conclusion: the neoliberalization of a regime or installation of a regulatory standard-setting arrangement responsibilizing the industry, takes place where and when this arrangement gains legitimacy as a tool and way of handling an issue. This happens incrementally, through gradual changes and hybridization of the existing regime, much more than allout replacement of the regime. While the presence of a neoliberal ideology is certainly a contributing factor, neoliberalization is achieved when actors that act within the regime - among others the industry - transform its concrete policy workings.

In the remainder of the paper, I first review the literature and justify the interest there is in analysing regimes as ways of regulating. I then describe empirically the opposite trajectories of the WHO programme and of the ICH, and the related shift in the approach of drug safety monitoring. The third section analyses these trajectories.

\section{REGIMES AS WAYS OF REGULATING}

From a global governance perspective, the globalization of pharmaceutical regulation is the result of two factors (Vogel 1998). The first is the globalization of the political economy itself, embodied by the rise of specialized and highly internationalized pharmaceutical firms and the increasing number of pharmaceutical products that are marketed worldwide. The second factor, more political in nature, is the move of governments towards more international regulatory cooperation. This move, in turn, has three explanations (Vogel 1998, p.18): the effort that European countries have pursued, since the 1960s, to create more convergence between national standards; the political pressures for more rapid drug approval in both Europe and the United States; and the experience of international cooperation itself in the very first meetings of the ICH.

Vogel's analysis shows that the emergence of a global regulatory regime correlates with the redefinition of state institutions as agents of 
transnational structures and markets, and the associated functional pressures on states to contribute to the development of such structures. It also underlines the role of the transnational industry in these developments, both independently and through lobbying of domestic institutions. It illustrates the political negotiation of the values and goals ascribed to the global regime by the various stakeholders, resulting in the promotion of access to products as a new overarching goal. Overall, it helps explaining the actual neoliberalization of the control of pharmaceuticals, that is the more effective application of industry preferences for quicker access of drugs to the market and relaxation of standards, owing to the capture of the international regulatory institution of the ICH by the industry (Abraham and Reed 2001, 2002; Abraham 2004, Abraham and Ballinger 2012).

The application of an international regime complexity perspective (Raustialia and Victor 2004) would lead to a similar observation. The area of pharmaceuticals control is very much a regime complex, since other institutions and collectives than regulatory agencies and firms, the representatives of which form the ICH, carry out the tasks of effectively controlling the safety, quality and efficacy of pharmaceuticals, such as the WHO. The launch of ICH and the production of more and more rules within this forum appear to be a by-product of the growing regulatory action of international firms, which shows in parallel agreements concerning intellectual property such as TRIPS (Helfer 2004, 2009) but also access to medicines for southern countries by the WHO or development of medicines for neglected or orphan diseases. The literature on regime complexes is interested in 'array[s] of partially overlapping and non-hierarchical institutions governing a particular issue-area' (Raustialia and Victor 2004). It looks at the institutional mechanisms such as strategies of forum-shopping (Raustialia and Victor 2004, Busch 2007) and regimeshifting (Helfer 2004) or orchestration (Biermann et al. 2009, Abbott and Snidal 2009), that bear on the level of integration, coherence and overall direction of a regime complex. This literature also shows that the policy logic underpinning global regulatory dynamics is predominantly neo-liberal. Research on climate, carbon capture, genetic resources, sustainability or genetically modified organisms (Raustiala and Victor 2004, Bartley 2007; Kleinman and Kinchy 2007; Reid 2013; Zelli et al. 2013) all demonstrate that regime complexes are overall informed by a neo-liberal logic. They tend to align on the idea that a free market is more optimal than pervasive public interventions, and result in the adoption of policy tools that contribute fulfilling industry perspectives on product circulation and market expansion. The generalization of this movement resonates with what Ruggie calls the end of 'embedded liberalism' (Ruggie 1998), namely the fact that the world has undergone a broad epochal change towards more neo-liberalism, observable in international policy affairs 
too. It illustrates a broader historical shift towards more market-oriented regulatory policies at the global level, and the fact that international regimes tend to reflect a different type of grand social compromise that the one which prevailed until the 1980s (Bernstein and Pauly 2008) ${ }^{5}$.

One of the angles from which the intertwined logics of neoliberalization and regulatory globalization have not been investigated, is a more basic policy analysis one: international regimes or regulatory arrangements are arguably legitimated by their putative effect on a given problem. Be they private or not, it is because they have this legitimacy that they are accepted and eventually institutionalized. Accordingly, one can then assume that the fact that a regulatory arrangement partakes in the emergence of a given way of regulating or acting on an international problem, is a condition that explains the fact that it constitutes the heart of a nascent international regime.

One way of doing so is to modify what is understood by regime to emphasize its policy dimension. For Krasner, a regime is a set 'of implicit or explicit principles, norms, rules, and decision-making procedures around which actor expectations converge in a given issue-area' (Krasner 1983). But regimes may include tools, practices and animating ideas about how to tackle an issue, to further approximate what is considered a regime by policy scholars (Elkin 1986; Hood et al. 2001). From this perspective, a regime resembles what Gaudillière and Hess call a 'way of regulating' (Gaudillière 2009; Gaudillière and Hess 2012). The way in which an issue is collectively managed (and not regulated in the restrictive sense of setting and enforcing standards) can be characterized in four dimensions. The first is the value or aims of the policy (compliance, public health, competitiveness...). The second is the tool of regulatory intervention. The type of evidence that is used to define and legitimize regulatory measures (animal experiments, statistical human trials or epidemiological studies) is the third component, the fourth being what Gaudillière and Hess call the 'social sphere', that is the dominant actors or operators of the policy intervention (corporations, professional societies, national public administrations, non-governmental organizations...).

The strategy in the remainder of the paper is to tell the intertwined histories of the WHO programme for international drug monitoring and of the $\mathrm{ICH}$, paying attention to the dimensions that are constitutive of a way of regulating in Gaudillière and Hess's framework, as it helps capturing the global policy context within which regulatory standard-setting, as done in $\mathrm{ICH}$, emerges as a legitimate tool. It thus appears that the centralization of international activity on drug safety in ICH and the globalization of regulation are inseparable from a set of other changes in other dimensions of the regime. Not only has the main tool changed towards a more explicit use of negotiated regulatory standard-setting in an international forum. Tool change correlates with the attention given to 
the issue of quicker access to products (aim/value), but also with the belief that the safety of medicines will be more objectively assessed through industry data and studies (form of knowledge), and with the emergence of public organizations that specialize in the setting and enforcement of standards in a particular audience, which is the industry.

The data that is used to reach this conclusion come from two sources. First, interviews were conducted with people in charge of drug safety monitoring in regulatory agencies in Europe and in the US, as well as in the European Commission, at the WHO and the UMC. About ten different medical experts with a long history of participating in international meetings on pharmacovigilance, at the $\mathrm{WHO}$ or in $\mathrm{ICH}$, were also interviewed. The data on firms came from interviews with two post-marketing safety officers working in large European firms, and from the archives of the firm Geigy. The present study is not based on a full survey of the engagement of firms with international pharmaceuticals control, indeed a difficult research to conduct given accessibility issues. The archival records of the WHO however allowed collecting precise historical information about how firms engaged with the WHO drug monitoring programme. For this research, I explored the archives of the WHO related to pharmacovigilance, drug safety and medicines policy more generally, covering 1964 to $1988^{6}$, providing great details about the activities and people of the UMC, of the WHO Pharmaceuticals Unit in Geneva, as well as of other actors (pharmaceutical firms, national ministries, hospitals) corresponding with those.

\section{THE WHO AND THE ICH: OPPOSITE POLICY TRAJECTORIES IN INTERNATIONAL PHARMACEUTICAL SAFETY CONTROL The origins of international pharmacovigilance}

The safety of medicines is regulated through two types of controls. On the one hand, regulators review the safety of drugs as established through pre-marketing toxicological and clinical testing by pharmaceutical companies, following laws and guidelines established by regulators. On the other hand, post-marketing surveillance or pharmacovigilance serves to collect data about adverse drug reactions and result in regulatory decisions, such as revision of marketing authorizations and of labelling, or (much more rarely) withdrawal.

The first attempt to organize drug safety monitoring at the international level was based on the notification, collection and analysis of reports of suspected adverse drug reactions by physicians. It originated in the aftermath of the thalidomide disaster in the 1960s. The substance thalidomide (commercial names Contergan ${ }^{\circledR}$, Grippex $^{\circledR}$ or Distaval ${ }^{\circledR}$ ) 
was developed by the German company Grunenthal, and massively marketed across the world for all sorts of clinical indications. This product was widely used, in quantities comparable to aspirin. Among other uses, it was prescribed to pregnant mothers as a solution to morning sickness. In 1961, Dr McBride, an Australian physician, reported in a medical publication an observed increase of $20 \%$ of phocomaelia (shortening of the limbs) in newborns, correlated with the intake of thalidomide. This publication alerted other physicians across the world, notably Dr Lenz in Germany. The convergence of observations by these two physicians led to the confirmation that thalidomide was causing these malformations. This discovery initiated a 'policy tragedy' (Carpenter 2010), and had a direct impact on ongoing legislative discussions in the USA, towards the institution of mandatory pre-market safety and efficacy drug reviews. The very way in which the epidemics was discovered (via concurrent medical publications) inspired physicians with the idea that the systematic exchange of observations by physicians and their centralization in a common database could result in quicker identification of adverse events and ascertaining of causalities, even in cases of infrequent and dispersed adverse events.

In 1962, the American Medical Association (AMA) tested a countrywide reporting programme, based on the reporting of suspected adverse drug reactions by hospitals. Five years later, the programme was made official through an agreement between the FDA and the pharmaceutical industry. In May of the same year, the World Health Assembly (the assembly of representatives of WHO's member states) adopted a resolution requesting a study of the means for rapid transmission of information concerning adverse drug reactions to national health authorities. In 1963, the Assembly adopted a further resolution, requesting to take action without delay to accelerate the dissemination of such information among national health authorities, so that the latter may take rapid decisions to restrict the use of or withdraw medicines with proven safety problems. This resolution required the WHO to study the feasibility of a collection of this information at an international level. It also invited the member states to put in place national systems for the collection of adverse drug information, similar to what the USA experimented. In the UK, the 'yellow card scheme' (named after the yellow forms which physicians across the country used to report their observations) was launched in 1968 (Inman 1993). Similar systems were put in place in Australia, Canada or Czechoslovakia.

The WHO took the decision to set up a pilot centre to develop and run a monitoring programme in 1967. The centre made an operational start in February 1968, with ten member countries (Australia, Canada, Czechoslovakia, Federal Republic of Germany, Netherlands, Ireland, New Zealand, Sweden, United Kingdom and United States), represented by the professor 
of medicine (generally a pharmacologist) that headed the corresponding national surveillance centre. During those years, the centre focused on developing the various tools that were necessary to the functioning of the central database. The first of these tools was a standardized form for reporting of adverse drug reactions, to be used by national centres, for data to be consistent and rapidly processed. The second working tool was a dictionary of all known adverse drug reactions, classified by organ. This terminology was supposed to help harmonize the description of effects and reactions in the report, for easy retrieval and analysis in the database. The dictionary will soon be known as WHO-ART (for Adverse Reaction Terminology). In parallel, a third tool started to take shape: a drug dictionary (now WHO Drug Dictionary). This dictionary was also instrumental for a reliable analysis of adverse reactions, and more importantly for imputation of these reactions to drugs ${ }^{7}$. Other tools were developed, such as various algorithms to create a signal in the case of a rapid increase in notifications concerning a given medicine, as well as various publications. Even though the centre was only at an experimental stage, and strictly limited in its resources and thus in its early achievements, those tools - the forms and dictionaries in particular - later proved instrumental for the development of pharmacovigilance internationally, including by firms.

By 1969, the project was already deemed a success (Venulet and Helling-Borda 2010). However, there were notable difficulties. The funding of the centre had become an issue, since the US government had refused to fund it beyond 1968. Competent staff was also lacking. WHO officials toured American hospitals, insisting with doctors and professors that they direct potential applicants with relevant medical and statistical expertise, only to be faced with the answer that no acceptable candidate could be found.

The WHO found itself obliged to look for other funds to be able to move to full functioning of the centre. Member countries were asked to fund the programme themselves. To limit the costs of it, the WHO decided to repatriate the centre within its headquarters in Geneva by the end of 1970. During the period extending between the move of the centre of Geneva and its relocation in Uppsala in 1978, more countries joined the programme. (There were 20 member countries by the end of 1974, that is after France and Japan joined.) The centre became better known not for its analyses of drug reactions or major drug safety alerts but rather for methodological developments in the science of 'pharmacovigilance', then in its infancy. The centre benefited from an influx of drug safety expertise from the transnational network of medical scientists and pharmacology professors supporting it.

One difficulty came from the opposition of the pharmaceutical industry. The pharmaceutical industry in general did not support the WHO programme, and even fought against it. The firm Geigy actively worked 
against any temptation to give powers to the WHO to recall drugs based on the data collected through its programme. According to this company, the latter should remain a medical programme, aimed at improving the use of therapeutic products, not one with regulatory impact.

Technically also, the hopes that the database could function as a sort of automated detection device, thanks to its large statistical base and powerful IT instruments, gradually declined along the 1970s. The enthusiasm around the principle of computer-aided statistical analysis of drug safety data, as a way to prove the responsibility of drugs in causing an adverse health event, and thus in motivating health authorities to authoritatively recall drugs, slowly started to diminish. Even though the database kept growing, the centre was only issuing a small number of interesting signals or alerts for national authorities. National health authorities also had to complain, at times, about the ambition of the staff of the centre to publish papers in medical journals about key adverse drug reactions, using confidential and proprietary safety data provided by national health authorities and by pharmaceutical businesses. The officials in WHO headquarters continuously complained about errors in the coding of drugs and classification of reactions, of poor medical analysis, as well as of poor printing quality of the documents distributed to national centres. The WHO's senior office for pharmaceuticals policy in Geneva also criticized the lack of capacity for medical research, minimal competences of the pharmacist and IT technician of the centre, as well as the membership of its scientific advisory board.

\section{Shifting agendas and WHO policy}

From 1975 onwards, WHO officials in charge of the programme started to express doubts about its value and the benefits for the WHO of supporting its development. The WHO soon stopped investing in its drug safety policy. It delegated the running of the programme to the Swedish government in January 1978, when a 'WHO collaborating centre', funded by the Swedish social and health affairs ministry, was created. The Uppsala Monitoring Centre (UMC), as it came to be known, was to run the WHO programme, with limited financial support (around 10,000 dollars to cover printing and publication costs) but strong policy supervision from the WHO headquarters - which retained most policy prerogatives, such as the definition of the programme's objectives, and management of relations with member countries.

The disinterest of policy managers at the WHO headquarters for drug safety must be understood in the context of the rise of another agenda of the WHO: that of the access to essential medicines. As Davies makes clear (Davies 2010), the leadership and overall contribution to global health of the WHO evolved through various phases. From WHO's establishment 
in 1948 to the mid-1970s, the organization focused on developing massive vertical programmes, building on critical technical-medical advancements. As Halfan Malher became director general in 1973, these sectoral programmes made space for a more horizontal and global strategy of providing minimal health welfare to all populations around the world. This strategic shift reflected in the declining interest for the medicines safety programme, and the promotion of the essential medicines policy. This was inaugurated by a resolution of the Assembly of 1975, calling for the WHO to provide support to developing countries in the selection and distribution of pharmaceutical products of sufficient quality, and at a reasonable price. The first list of essential medicines was published in 1977. The Alma Ata conference of 1978 established the access to essential medicines as one of the 8 constitutive elements of a primary care system (Laing et al. 2003) ${ }^{8}$. Sten Olsson, a pharmacist who has been with the UMC since the early 1980s, observes that the WHO simply overlooked the issue of drug safety after the signature of the memorandum with the Swedish government in 1978: 'Drug safety never was a priority in WHO $\mathrm{HQ}$, that always focused more on access to medicines and essential medicines. [...] WHO basically sold it out. ${ }^{9}$ In retrospect, perhaps the most perceptive and straightforward summary of events is that given by the person in charge of pharmacovigilance policy at the European Commission in the 1990s: 'In reality, there was a strong impetus after thalidomide, but it did not last.'10

One factor was instrumental in the evolution of WHO's positioning towards the problem of drug safety, and also explains the later rise of ICH: the development of private, industrial pharmacovigilance. The importance of this involvement of firms in regulation can be seen in a policy memo that the senior policy officer and future chief of the pharmaceuticals unit at the WHO headquarters, John Dunne, sent to the director general of the WHO in 1984. In this memo, written at the very moment when the UMC was gaining autonomy, Dunne informed his director general of a strategic new development, which he called upon to give support to:

Conditions have changed radically since the scheme [the monitoring programme] was introduced. Pharmaceutical manufacturers are now widely required to assume responsibility for monitoring their products as a precondition of marketing. They are also, in some cases, required to apprise regulatory authorities on a timely basis of all serious reactions attributed to their products wherever they may have been reported. Thus, a large majority of reactions now reported in the United States derive from manufacturers. These changes, and the ascendancy of epidemiologically-based approaches to drug monitoring, create a need to embark on a 
broader review of existing mechanisms and I attach, for information, a project proposal that I am now developing in conjunction with CIOMS. ${ }^{11}$

This letter sketched out a number of dramatic developments concerning drug safety. The first is that drug safety was increasingly becoming a regulatory domain in and of itself, and what is more a global one. In effect, more and more countries were then contemplating to condition the delivery of marketing authorization to obligations of monitoring of adverse reactions occurring after marketing of the drug. This new rule was a blow to the very design of the programme: given the likely increase in reporting of information by manufacturers, the industry will gradually become a more comprehensive source of data than physicians.

The second is that national authorities would most likely be in the position to request pharmaco-epidemiological studies from manufacturers, making spontaneous notification systems potentially redundant. In contrast with clinical trials, the number of people actually taking the drug is not known, hence the proportion or frequency of the adverse drug reaction out of the total number of prescriptions of the drugs cannot be computed. Secondly, the adverse drug reaction is only in the first place an adverse health event, which is not with certainty caused by the drug, but possibly by a host of other factors on which no data is available in the database. Missing information can be reconstituted if the data analyst has medical, clinical experience, or a close contact with the practitioner that observed the event. But this is generally an imperfect method, and in any case it minimizes the efficiency of data mining as this knowledge cannot be encoded. Last but not least, it is estimated that only $10 \%$ of physicians actually notify the suspected adverse drug reactions they observe (Leiper and Lawson 1985). When they do, they probably only report a fraction of what they observe. All of the above are definitive limits for the detection and action on adverse drug reactions through spontaneous notification systems, that have become increasingly obvious to drug safety researchers as years passed (e.g. Barnett and Woods 1987; Tubert et al. 1992).

The letter also boasts an initiative of the Council for the International Organization of Medical Sciences (CIOMS). The CIOMS is a permanent consensus conference of the medical profession, with close links to the WHO (which hosts its meetings and publishes its proceedings) and the UNESCO. It is the forum within which such international rules or charters as the one that forbids the use of human subjects in medical experiments were developed. A group of pharmaceutical companies chose this venue for its projects to proactively develop international pharmacovigilance standards ${ }^{12}$. These companies were reacting to the recent request 
by the FDA to report all information concerning serious adverse drug reactions occurring worldwide, within 15 days. They knew all too well that they did not have the tools to collect safety information in a standardized manner from across the world on all of their products. They also anticipated that other regulators would emulate the FDA. At about the same time, the heads of national pharmacovigilance systems in Europe had indeed started to meet regularly within a 'pharmacovigilance working party' under the aegis of the European Commission, exchanging ideas about harmonized European rules in the matter.

The first CIOMS meeting on pharmacovigilance took place in 1984, and was dedicated to the elaboration of a standardized form for the reporting of suspected adverse drug reactions, and the establishment of a terminology - similar to what had been undertaken as part of the WHO programme. The second CIOMS session, extending over the second half of the 1980s, focussed on the development of a guideline for establishing periodic safety update reports (PSUR): a report that collects and analyses all incidents related to a given drug, at regular intervals (e.g. 5 years). The PSUR standard was integrated into EU law in 1993. It was also a prefiguration of the future 'risk management plans', which the ICH formatted just a decade later. ${ }^{13}$ That standard had a major impact on firms, by forcing them to put in place resource intensive processes of collection and analysis of data, infrastructures of traceability of products and uses, as well as dedicated services. This standard contributed to a massive transfer of analytical work from public agencies to firms. Since the WHO does not have the power to request those data, the UMC does not collect them. Vigimed was thus deprived from the most substantial sets of data on drug safety available.

The WHO did not and still does not have the legal power to regulate the pharmaceutical industry, and was not seeking to obtain such powers from member states at the time. The CIOMS project was thus advantageous for the WHO: it allowed it to participate in transnational regulatory developments. Furthermore, the WHO could obtain from the CIOMS the sort of results that the UMC had so far failed to offer: the development of accepted and reliable technical standards for global reporting of drug safety information. Importantly also, the industry accepted to fund the series of CIOMS meetings, allowing this project to run without the money of the WHO's pressured core budget ${ }^{14}$. Overall, this was an opportunity for the WHO to maintain minimal activity in the area of drug safety, and to free resources to advance on the other policy front of the access to essential medicines.

\section{Towards global standards and operations}

The establishment of a European regulatory regime for pharmaceuticals further accentuated the opposite trajectories of the international 
monitoring programme and of the nascent regulatory work around international standards.

The process of Europeanization of national pharmaceuticals policies in Europe accelerated in the second half of the 1980s, as part of the process of creating the internal market. It is around this time that the European Commission, led by Fernand Sauer for that matter, decisively shaped the two-level system for the common licencing of medicines that was eventually adopted in 1993 (with a centralized procedure run by the European Agency, and a decentralized procedure coordinated by member states). According to Sauer's vision, the integration of the regulation of medicines at the European level was a necessity to evaluate increasingly complex and globally distributed products. A European agency pooling the available national expertise would have far greater weight towards the increasingly internationalized industry and the gold standard of pharmaceutical regulation, the US Food and Drug Administration. This vision gained tractability as European national administrations similarly engaged in the creation of agencies specialised in regulatory operations for pharmaceuticals, such as the UK in 1989 or France in the early 1990s. These sorts of agencies soon hosted and ran national systems of collection of adverse drug reaction reports and databases. By competing and interacting among themselves, national regulatory agencies allowed the development of a common European space for the regulation of pharmaceuticals (Hauray 2006; Hauray and Urfalino 2009).

One of the first concrete consequences of the Europeanization of pharmaceutical regulation as regards pharmacovigilance and the WHO programme is the development of a common European database of adverse drug reactions, EudraVigilance. The setting up of Eudravigilance was foreseen by the European regulations adopted in 1993 to create a European licencing system. More than a decade was necessary to make it fully operational, with routine data transfer between national databases and Eudravigilance. But it is now a more comprehensive than Vigimed, since European Union member states, and thus companies that report to them, contribute their data to it. In reality, it was developed in full awareness of the fact that it would eventually duplicate and soon make Vigimed redundant. For Sauer, the EU had no other choice but to build its own database, in so far as the UMC was not technically capable of transmitting back to the European Medicines Agency the reports that were sent to it by the various member states of the programme, and that the database was imperfect (duplications, gaps...). The issue of the collaboration with the UMC and of the interconnection between Eudravigilance and Vigimed was dealt with only after the Eudravigilance was fully up and running. It was not until 2003 that an official of the European medicines agency started to attend the annual meetings of the programme in Geneva. The automated transmission of adverse drug reaction reports 
from Eudravigilance to Vigimed was only effective in 2015, nearly 20 years after the European medicines agency pledged it would fully cooperate with the WHO on pharmacovigilance issues (EMEA 1998). The EMA did make sure not to interfere in the relation between the UMC and European countries that were part of the programme. ${ }^{15}$

Eventually, Eudravigilance has de facto replaced Vigimed for most countries, including southern countries: they first consult the former when they are in search of information on a product. Vigimed is a large database, but $60 \%$ of its reports come from the USA, making it unrepresentative and unfit for detecting signals. Also, the database only contains data collected from professionals, who reportedly notify only about $10 \%$ of the adverse drug effects they encounter in medical practice. This lack of completeness and representativeness make it unlikely for this database to generate robust and confirmed signals of adverse drug reactions, which other databases would not spot.

A second concrete consequence of the rise of a Europe for pharmaceuticals is the acceleration of the ICH process itself. The Europeanization of national regulatory activities was but one element of an on-going globalization of pharmaceuticals control, to which Sauer thought Europe should decisively contribute. He did put his weight in the launch of the ICH process $^{16}$. The ICH became a space for cooperation between regulatory agencies, including on pharmacovigilance. Projects that overshadowed the work of the UMC and of the WHO programme emerged there, notably that of creating a common dictionary of regulatory terms.

In 1992, the UK medicines agency took the initiative to propose to other ICH countries to generalize the use of its own dictionary of medical terms, MEDDRA (MEDical Dictionnary for Regulatory Affairs), without considering how this initiative would effectively shut off all efforts to develop and use the WHO terminology. This initiative shocked the UMC and the experts associated to the programme, as it simply risked killing the UMC: since the early 1980s, it had started to live off the money made selling its dictionary and terminology to firms for their own internal use and databases. The European Commission and other ICH participants accepted the UK proposal, on the grounds that it was already operational for the transmission of reports between the US and the UK. The European Commission official in charge of pharmacovigilance issues, in retrospect, minimizes the conflict that soared around this issue, but still recognizes that hard battles were fought between institutions and dictionaries.

Even if MEDDRA is in part structured around the hierarchy of terms designed by the experts of the UMC for the WHO-ART dictionary, it is slowly evolving as a very different product. WHO-ART requires less training in the use of dictionaries, because it uses more generic descriptions of adverse drug reactions and fewer terms. MEDDRA is maintained and distributed by a committee comprised of representatives of the 
industry and of regulatory agencies, under the aegis of $\mathrm{ICH}$, something which the people at the UMC call a technocratic approach, which contrasts with the inclusive approach of the UMC and WHO, towards developing countries specifically. WHO-ART itself has become less used, at least by regulatory agencies of the North and by firms ${ }^{17}$.

There is thus a clear discrepancy between the WHO/UMC and what developed through ICH. This was further compounded by the fact that the WHO has only an observer status within the board of MEDDRA and $\mathrm{ICH}^{18}$ and that it refused to take a leading position in the process. It did not defend either the value of the tools developed by UMC, which may have served as a working basis for new ICH standards. It reduced its role to sensitizing this forum to the heavy requirements in technical, analytical and human resources that many of the rules that are being adopted in ICH imply for developing countries. The UMC retains a particular importance as provider of the WHO Drug Dictionary, of various commercial services for data analysis, and also as centre of reference for developing countries (providing training and infrastructure support for the development of drug safety policies), ${ }^{19}$ but is broadly speaking peripheral in the global regime for drug safety, which has turned much more administrative and rule-oriented than it was when the WHO launched its monitoring programme.

The adoption of a guideline for 'pharmacovigilance planning ${ }^{20}$ in ICH was the second major incursion of the ICH in matters of pharmacovigilance. The guideline was transposed in the EU and in the USA as a requirement to firms to produce risk management plans (in the EU) or risk minimization action plans (in the USA). This is the materialization of the transnational expansion of an approach of drug safety in terms of 'risk management' (FDA 1999; EMEA 2005). Risk management emerged at the US FDA as a new strategy to respond to the increase of drug withdrawals in the 1990s - and to the pressure of firms and Congress to curb it (Demortain 2008; Davis and Abraham 2011). It is based on two fundamental ideas. The first is that post-authorization safety management can be improved by anticipating the safety problems that clinical trials signalled in the pre-marketing phase, or that they on the contrary failed to document. Firms should be able to use this knowledge base to plan safety management activities to implement in the post-authorization phase. The second is that the continuous monitoring of safety problems should lead, in case of actual problems, to retarget the use of the drug rather than to withdraw them from the market. In short, risk management is pharmacovigilance reinvented through the frame of marketing authorization: based on data generated at this stage, and designed by firms and regulatory agencies, who have a concurrent interest in defending the credibility of marketing authorization decisions (Carpenter 2010). 
Tellingly, the very drug safety researchers who contributed to develop the concept of pharmacovigilance planning as a form of evidence-based pharmacovigilance (Waller and Evans 2003) thought that the adoption of this guideline was hasty and opportunistic (there was a consensus on the idea, and the ICH was seeking topics on which to produce new standards). The net benefits of generalizing such tool in the industry globally for saving lives and reducing morbidity were not demonstrated. This complaint reflects a broader feeling of hospital physicians involved in pharmacovigilance in the pre- $\mathrm{ICH}$ era that the $\mathrm{ICH}$ now supersedes other forums, such as learning or professional societies, in which drug safety methodologies were validated scientifically and medically, ahead of any form of codification.

\section{GLOBALIZATION AND SHIFTING WAYS OF REGULATING DRUGS}

The current global regime for the control of pharmaceuticals is, as is clear from the literature and also from the above history, centres on the activity of the ICH and of its members - regulatory agencies and firms. It is embodied by the high level of acceptance of the harmonized rules that are adopted within this forum.

The global regime for pharmaceuticals is not without some complexity. Although the WHO and the UMC have declined, they have not disappeared from the picture. They represent a sort of sub-regime, in the sense that spontaneous notification is one mode of performing pharmacovigilance, which itself is only one instrument of drug regulation. They fulfil complementary or 'support' functions (development of the drug dictionary, training in drug safety systems of southern countries), but are little influential in drug withdrawal decisions and risk management.

There is also more interaction and cooperation between governments and between firms through ICH where pharmaceutical safety is concerned, than through the WHO programme. More decisions about products are made through ICH standards, than derived from the activities and people of the WHO programme - despite initial ambitions to the contrary. The globalization of rules for registration and post-marketing surveillance is driven by regulatory agencies of the northern hemisphere and multinational firms that develop product primarily for these markets. On the contrary, there is a form of discrete 'global South' network of countries, the problems of which are considered through other forums, such as the WHO and the UMC. The latter's preference for the problems of developing countries makes full sense only in the light of the retreat of the WHO from issues of pharmacovigilance and from the ICH more generally, but also the voluntary shift of the UMC and the staff running the WHO programme towards the promotion of drug safety policies in southern countries. 
The picture of the global regime thus obtained is one in which there is a clear hierarchy between actors, problems and tools for pharmaceutical control. The $\mathrm{ICH}$, associated regulatory agencies of the global North, multinational companies, clearly took precedence over other actors like the WHO. An approach in terms of 'ways of regulating' helps highlighting the multiple dimensions of this shift, and its incremental nature.

The central shift in the above story is the fact that public organizations have changed tool to control products. Besides running and organizing systems of surveillance themselves, they now set standards for the industry to perform surveillance and risk management. The decline of the international monitoring of adverse reactions by means of spontaneous notification is in part explained by the technical challenges facing the WHO programme, but also the lack of political and financial support on behalf of the WHO HQ. The context of this lack of support is the growing investment in the tool of standard-setting for market authorization and surveillance. From the 1950s onwards, internationally, more and more governments have put in place precise formal requirements for data to be presented before any use of the product by patients, resulting in the emergence of a standard system of marketing authorization (Carpenter 2010). In the history above, this change materializes with the creation of an EU licencing system. The rise of the tool of marketing authorization also reflects in the activity and organization of major pharmaceutical firms, most of which have developed massive $R \& D$ and regulatory affairs departments to be able to interact with regulators during the generally stringent process of evaluating of the toxicological and clinical data produced in support of their applications. From the 1970s onwards, firms collectively invested in the development of rules for pre-marketing testing of their products, and in lobbying regulators that were establishing such norms.

What the history recounted above illustrates is that the use of the tool of standard-setting gradually extended from the question of marketing authorizations and preliminary tests to obtain this authorization, to the issue of post-marketing safety. The result of this shift is a re-structuring of the control of pharmaceuticals in terms of a divide between pre- and post-marketing controls, which greatly redefined what surveillance or monitoring of drug safety means. As marketing authorization assumes a greater importance in national laws and guidelines, in the work of regulatory agencies and in the internal organization and resources of firms, pharmacovigilance became the activity of checking out on marketing decisions in the light of drug use data - or 'risk management'. Given the proprietary nature of the safety data, but also the difficulty for spontaneous notification systems to prove causal relations between an adverse event and a drug, the preferred process evolved towards firm-controlled epidemiological studies and risk management. Spontaneous notification 
systems were never conceived by the medical profession as an auxiliary to the main mode of regulatory control, registration, but as a sui generis system of professional learning and improvement in the use of therapeutic products.

This shift in the preferred tool for controlling pharmaceuticals then connects to several other evolutions, all of which contribute to explain the launch of the ICH process and the establishment of global standards for registration and post-marketing surveillance of products.

One of these evolutions is emphasized by Vogel (1998): it concerns the aims and values underpinning the control of pharmaceuticals. The globalization of regulation corresponds to an agenda of rapid international access and approval of medicines. When approaching this dimension from a historical perspective and from the outside as it were, that is from the WHO's view-point, one can see that the problem of the safety of medicines has waned to be associated to a notion of access to medicines (essential ones as concerns countries in the South, innovative ones as concern the North). Safety has become less of a problem of potential disasters affecting the public and its health, and more of a technical criterion for the evaluation and circulation of drugs. This is precisely the vision of the problem of safety that is embedded into the rising tool of risk management and pharmaco-epidemiological studies: safety as a condition defined by pre-marketing tests and trials that must be validated or verified ex-post, through dedicated protocols.

The second dimension to which the shift in tools connects, which also explains the globalization of control through ICH standards, is that of knowledge and evidence. The story of the WHO programme and of the UMC contains various indications that spontaneous notification systems run by health professionals failed to produce globally accepted knowledge about drugs and their adverse reactions. The failure of the programme opened the possibility for a redirection of WHO's agenda and resources towards the CIOMS and later the ICH. It contributed to prove that one tool (collection and analysis of safety reports by professionals) could not be effectively organized internationally, and that other tools should be preferred.

On the contrary, post-marketing safety being so critical for the preservation of their markets, firms have engaged in the development of infrastructures, competences and rules to run post-marketing safety studies, or at least to collect data about their products in view of reporting them to regulators. The CIOMS initiative and the industry's purchasing of the terminologies and dictionary developed by the UMC both exemplify this. The result is that firms and regulatory agencies reached a level of standardization of information and methods of interpretation that was never achieved within the WHO programme, which supports the sort of 'mechanical objectivity' (Porter 1992) - that is, objectivity deriving from 
the application of agreed-upon rules and protocols, as opposed to objectivity derived from professional expert judgment- that is required to be able to use safety data as evidence to take regulatory measures transnationally. Quasi-experiments like pharmaco-epidemiological studies are considered to have more reliability and objectivity to them than systems of data collection, in which agents are notably more difficult to enrol. With this epistemic change, the approach of the WHO, that conceived of adverse drug reactions as epidemics, to be monitored and controlled by professionals in the field, lost mileage.

The third factor of globalization to which a tool shift connects is what Gaudillière and Hess call the social sphere, or the actors that are deemed legitimate to be in charge of the intervention.

As detailed above, the WHO minimized its involvement in the monitoring programme and drug safety agenda more generally. It did not embrace, and did not become an actor in the new ground on which this issue got dealt with, that of the international harmonization of requirements for the assessment of the benefits and risks of medicines. On the other hand, the disaffection for spontaneous notification and the rise of a more mechanical and standardized form of post-marketing surveillance coheres with the 'agencification' movement in Europe, that is the creation of more national regulatory agencies. Agencification means that national administrations are established which, more than preceding ministries, specialize in and depend on the existence of rules, are also faced with the need to assert their authority towards the regulated entities. Again, tools that produce regulatory evidence, better than what experience has shown spontaneous notification systems to be able to do, are preferred by agencies. The priority given, in the UK particularly, to the development of rules for post-marketing safety studies exemplify this.

Another change at the level of actors, touched on above, is noticeable in the kind of experts that populate transnational policy networks. The WHO programme and the UMC have typically mobilized hospital physicians, who systematically gave a central place to the therapeutic exercise and the scientificization of their use of medicines. These experts have increasingly felt disconnected from the world of $\mathrm{ICH}$, which is populated by physicians with dual competences and experiences in medicine and science on the one hand, and with the development and application of regulatory standards on the other hand.

The establishment of an international standard-setting process, with greater weight to industry involvement and to a logic of harmonization and relaxation of standards is, from a historical and multi-site perspective, inseparable from a complex set of changes. Whether we consider the values and aims, evidence or personnel that prevail in the global control of pharmaceuticals, regulatory standard-setting appears to be a tool that coheres with the emergence of a new way of regulating, which is 
characterized by the consideration given to the objective of product circulation and market functioning alongside (or concurrently with) that of public health; the increasing weight given to standardized regulatory knowledge (risk management) over professional knowledge and information; the treatment of scientific and medical matters by regulatory institutions and firms that mobilize health professionals who had previously established and run a knowledge system for their own professional use and interest, independently from these organizations.

\section{CONCLUSION}

This paper analysed the historical transformations of an institution and tool, the WHO programme for international drug monitoring, which preceded the current international regulatory regime for pharmaceutical control. It did so to reveal factors of regulatory globalization and neoliberalization that one cannot discern when considering the regime synchronically and synthetically, as an ideology or set of values reflected in formal bodies of rules.

The paper shows that the globalization of pharmaceutical regulation produced a regime of harmonization of registration and post-marketing requirements by firms and regulatory agencies, because several other evolutions occurred at the same time that contributed to install and legitimize a new way of controlling drugs: one that proceeds through controlled safety studies aimed at confirming marketing authorizations, that operates under the assumption that such studies produce appropriate knowledge to inform regulatory action, and that is driven by regulatory agencies, firms and associated regulatory-scientific experts to maintain the rapid access of the public to drugs.

Both of the ways of regulating that develop under the WHO and under the ICH are transnational in their own sense, and prevail in different parts of the world: the ICH and its standards for post-marketing safety matter more in the North than in the South for instance, where WHO policies on pharmaceuticals continue to play a great role. But in so far as the global regime for pharmaceuticals regulation is embodied by the activities of the $\mathrm{ICH}$ and associated regulatory agencies (the American, European and Japanese ones), one may say that the administrative-industrial way of regulating drugs, and its specific tools, have globalized more effectively than other ways of regulating drugs. One may say that one is the major regime, the other a more minor one. The two are intertwined. The administrativeindustrial one emerged from and hybridized with the previous, professional one.

The case of pharmaceutical control is, like all case studies, too specific to inform a general theory of regulatory globalization. However, it helps highlighting a number of more general mechanisms that partake in and 
define the pattern of regulatory globalization that is observed. The paper basically shows, first, that the rise of a new regulatory arrangement, more neoliberal in its orientation, is the result of an endogenous transformation of regulatory regimes much more than an externally imposed new regime based on a policy script that would be 'foreign' to the domain in question.

A second finding is that neoliberalization is a process that takes place in several sites of action, not simply in one. Ideological action is certainly of importance, but in the present case, sites of concrete, technical standardization were key. The very fact that the industry effectively engineered standards for international transmission of pharmacovigilance reports did much to ensure that eventually, industry data and protocols were used in pharmacovigilance. Importantly, no overall scheme gave the direction and coordinated these changes. At times, visions of the overall shift that was happening emerged, as the letter of Dunne to the WHO Director General shows. But these rationalizations emerge from within the process. They are punctuated, and nothing indicates that conflicting visions did not emerge in other places.

One final element of conclusion concerns the action of the industry to manufacture these changes. Changes in the agenda (towards the problem of access to medicines) or in the standards of regulatory knowledge (towards more industry-based safety studies) are opportunistic transformations of the working of a regime by actors that have gained an understanding of how it functions and evolves. Actors of the internationalized pharmaceutical industry were among those, and did act to transform it, as the story presented above sporadically shows. This results concurs with what the most recent work on regulatory capture describes (Carpenter and Moss 2013): that policy outcomes are all the more concordant with industry preferences as the industry acts in an ubiquitous manner in various corners of the regime, 'corroding' the tools, sets of data and information as well as organizations of regulatory intervention.

This means that neo-liberalization is all the more effective as the industry (putatively the actor that most consistently promotes this sort of change) engages to change the regime incrementally at various levels. The changes described here being contingent and involuntary as much as intentional, it results that it is not fully appropriate to link the rise of neo-liberal, market-oriented arrangements, with the intended action or lobbying of supposedly united industry actors. Neoliberalization goes hand in hand with regulatory globalization in so far as the actors that push market-oriented arrangements get involved in the workings of the regime to modify it from within. However, market power is a key operator of regulatory globalization, in so far as those who own it use their capacity to transform the workings of the regime. It is certainly relative and contingent to the myriad factors that define these operations - and 
certainly creates a challenge for the students of those processes, given the difficult and limited access to firms operations - but no less effective in the long-run.

\section{ACKNOWLEDGEMENTS}

I would like to thank Christian Bonah, Soraya Boudia, Jean-Paul Gaudillière, Boris Hauray, Emmanuel Henry, Nils Kessel, Anne Rasmussen and David Vogel, with whom the present study was discussed at various stages of its development. Thanks also to Priya Bahri, Gaby Danan, Sten Olsson, René Royer and Fernand Sauer for highly informative and insightful discussions. I am particularly grateful to Allison Loconto for detailed and helpful comments on an earlier version of the article. The research was funded by the Institut Francilien Recherche Innovation Sociéte (IFRIS).

\section{DISCLOSURE STATEMENT}

No financial interest or benefit arises from this research for the author.

\section{NOTES}

1. The WHO broadly defines pharmacovigilance as 'The science and activity concerning the detection, evaluation, analysis and prevention of adverse drug effects or any other problem related to the taking of a medicine' (WHO 2002).

2. The WHO programme helps countries in their pharmacovigilance activities, but also centralizes all national safety data in a global database, to analyse larger sets of data and make the detection of rare adverse drug reactions more efficient - and the recall of unsafe drugs more effective.

3. In this that they follow the first three phases of testing that take place before marketing of the drug. See Carpenter 2010 for details about the institutionalization of this concept and practice of 'phased trials'.

4. At its origins, the $\mathrm{ICH}$ is a common initiative of industry associations and dominant regulatory agencies of the planet in the early 1990s to advance towards harmonization of the requirements of those regulators for putting drugs on the market. That process of standard-setting at the global level was imagined at the turn of the 1980s-1990s, and took off immediately after an initial meeting in Brussels in 1991. Through regular, highly attended meetings, the process gained momentum, and proved of great interest to all participants. While it was set to last only six years, it is still ongoing. It even attracted more participants (Vogel 1998; Daemmrich 2004).

5. This observation of the neoliberalization of various international regimes goes hand in hand with the analysis of the structure of power in the international political economy. In short, the articulation and promotion of neoliberal arrangements is effectuated by the actors that are shown to drive and influence the negotiation of international regimes or the dynamics of international regimes complexes: powerful international organizations such as the world bank or IMF for instance (Braithwaite and Drahos 2000; Broad 2006), 
sometimes associated with transnational policy networks (Goldman 2007); transnational industry groups that capture and influence domestic or international regulatory institutions (e.g. Lall 2012); or, in a neo-gramscian perspective, a transnational capitalist class which redefines the interests of national states (Harmes 2006; Eren-Vural 2007; Görg and Brand, 2000, 2006).

6. Jean-Paul Gaudillière also kindly shared a couple of records from the archives of the Swiss company Ciba-Geigy.

7. This dictionary is based on a unique identifier for each drug, the 'medical product ID', which allows to make correspondence across various types of classifications of drugs (by substance name, by proprietary name, by marketing authorization holder as well as by Anatomical-Therapeutic Classes). It provides dosage, countries in which the product is marketed, and so on. It is the dictionary of reference for regulators and for the pharmaceutical industry, as well as for the now vast IT industry that helps the former building internal product and distribution databases for its multiple products.

8. Fernand Sauer, who represented the French government in the WHA in the 1970s thus remembers that

Until the fall of the Berlin wall, the delegates of Eastern countries spent a good deal of time during official sessions disparaging multinational companies, and boasting the high quality of health care in their countries. Faced with multiple contradictory demands from member states, the WHO then gave priority to essential medicines and traditional remedies, and tended to consider that clinical trials and pharmacovigilance were issues that were specific to richer countries.

(Interview with author, May 2012).

9. Interview with author, June 2012. Olsson is a pharmacist by background, and a staff member of the UMC since its creation in 1978. He is now the chief officer for the WHO monitoring programme, splitting his time between Uppsala and Geneva.

10. European Commission official in charge of pharmacovigilance, interview with author, February 2004.

11. Letter of John Dunne to WHO's Director General, 'WHO Collaborating Centre for International Drug Monitoring Uppsala - Sweden', PHA/JFD/eor, $\mathrm{MIO} / 286 / 5,7$ August 1984.

12. Interestingly, the CIOMS project had been presented to John Dunne by Venulet, the former director of the WHO monitoring programme. After leaving the WHO in 1975, he joined the Swiss company Geigy, where he was in charge of drug safety issues. That very company had been among the first to disapprove, back in 1964, the project of giving an international WHO centre the power to take direct decisions to withdraw products following adverse drug reaction reports. Through his contacts with Dunne, Venulet obtained the support of the WHO headquarters for the CIOMS project.

13. In fact, the CIOMS later became a preparatory forum for ICH work. Several guidelines adopted by ICH were first conceptualized and sketched out within CIOMS, sometimes by the same participants.

14. Starting in the 1980s, several key Member-states such as the USA or the UK have started to provide money to the WHO through voluntary donations to extra-budgetary programs, rather than through the biennal core fund. A growing part of the overall budget of the WHO is thus directly attached to policy programs (Davies 2010). 
15. It was agreed in 1998 that EU member-states would have to send ADR reports to Vigimed as well as to Eudravigilance, but the UMC was requested at the same time to export the reports of Vigimed towards EudraVigilance. This rule was the object of a major conflict between the WHO and the European Commission.

16. According to Vogel, the EU has an interest in implementing global standards on its territory, since EU member-states generally agree on these standards in the first place. The EU is the area in which ICH guidelines are most directly and frequently applied (Vogel 1998).

17. The generalization of MEDDRA in European countries and later in $\mathrm{ICH}$ forced the UMC to modify WHO-ART, and to align many of its definitions with those of MEDDRA. This was even more imperative after 2001 when the US, the country from which the greatest part of Vigimed data originate, decided to switch to MEDDRA. It is now possible to query Vigimed using MEDDRA terms, which are more frequently updated than those of WHOART, thanks to the working groups of the 'maintenance organization' that the ICH set up for it. Since 2002, the UMC also aligned its dictionary with the norms for identification of pharmaceutical products developed in the European Committee for Standardization. In 2005, the CIOMS working group 1A and the ICH expert group ICH-E2b were put in place to standardize 'data sets for international exchange of adverse reaction information'. The UMC has to comply with the guidelines that result from this work.

18. Ralph Edwards, who was director of the UMC at the time of the dictionary battle, is also quite explicit about, and critical of, the strong desire to involve the pharmaceutical industry in ICH, and the ensuing difficulties for southern countries to appropriate tools and guidelines that are designed for countries with high levels of expertise and resources (source: Interview with author, October 2003).

19. The UMC employs 33 staff members for the development and distribution of the drug dictionary, 11 for consulting activities, and 7 for the work around the database.

20. That is, on the introduction within applications for the marketing authorization of drugs, of plans for activities of pharmacovigilance to be conducted after granting of the marketing authorization.

\section{NOTES ON CONTRIBUTOR}

David Demortain is a political scientist and sociologist at the French National Institute for Agronomic Research (INRA), based in the Laboratoire Interdisciplinaire Sciences Innovations Sociétés (LISIS). He is an associate of the French Institute for Research Innovation and Society (IFRIS) as well as of the Centre for Analysis of Risk and Regulation (CARR) of the London School of Economics. His research interests concern the production and use of science, knowledge and expertise in (transnational and European) regulation. Email: demortain@inraifris.org

\section{REFERENCES}

Abbott, K. and Snidal, D. (2009) 'The governance triangle: Regulatory standards institutions and the shadow of the state', in W. Mattli and N. Woods (eds) The Politics of Global Regulation, Princeton: Princeton University Press, pp. 44-88. 
Abraham, J. (2004) 'Pharmaceuticals, the state and the global harmonisation process', Australian Health Review 28(2): 150-60.

Abraham, J. and Ballinger, R. (2012) 'Science, politics, and health in the brave new world of pharmaceutical carcinogenic risk assessment: Technical progress or cycle of regulatory capture?', Social Science E Medicine 75(8): 1433-40.

Abraham, J. and Reed, T. (2001) 'Trading risks for markets: The international harmonisation of pharmaceuticals regulation', Health, Risk \& Society 3(1): 113-28.

Abraham, J. and Reed, T. (2002) 'Progress, innovation and regulatory science in drug development the politics of international standard-setting', Social Studies of Science 32(3): 337-69.

Barnett, D. B. and Woods, K. L. (1987) 'Post-marketing surveillance or drug acceptability study?', British Journal of Clinical Pharmacology 24(3): 281-2.

Bartley, T. (2007) 'Institutional emergence in an Era of globalization: The rise of transnational private regulation of labor and environmental conditions', American Journal of Sociology 113(2): 297-351.

Bernstein, S. and Pauly, L. W. (2008) Global Liberalism and Political Order: Toward a New Grand Compromise? Albany: SUNY Press.

Biermann, F. et al. (2009) 'The fragmentation of global governance architectures: A framework for analysis', Global Environmental Politics 9(4): 14-40.

Braithwaite, J. (2008) Regulatory Capitalism: How It Works, Ideas for Making It Work Better, Cheltenham and Northampton: Edward Elgar Publishing.

Braithwaite, J. and Drahos, P. (2000) Global Business Regulation, Cambridge: Cambridge University Press.

Broad, R. (2006) 'Research, knowledge, and the art of 'paradigm maintenance': The World Bank's development economics vice-presidency (DEC)', Review of International Political Economy 13(3): 387-419.

Busch, M. L. (2007) 'Overlapping institutions, forum shopping, and dispute settlement in international trade', International Organization 61(04): 735-61.

Carpenter, D. P. (2010) Reputation and Power: Organizational Image and Pharmaceutical Regulation at the FDA, Princeton, NJ: Princeton University Press.

Carpenter, D. and Moss, D. (eds)(2013) Preventing Regulatory Capture: Special Interest Influence and How to Limit It, Cambridge, MA and London: Cambridge University Press.

Daemmrich, A. A. (2004) Pharmacopolitics: Drug Regulation in the United States and Germany, Chapel Hill: The University of North Carolina Press.

Davies, S. (2010) Global Politics of Health, London: Polity.

Davis, C. and Abraham, J. (2011) 'A comparative analysis of risk management strategies in European union and United States pharmaceutical regulation', Health, Risk \& Society 13(5): 413-31.

Demortain, D. (2008) 'From drug crises to regulatory change: The mediation of expertise', Health, Risk \& Society 10(1): 37-51.

Demortain, D. (2011) Scientists and the Regulation of Risk: Standardising Control, Cheltenham and Northampton, MA: Edward Elgar Publishing.

Elkin, S. L. (1986) 'Regulation and regime: A comparative analysis', Journal of Public Policy 6(1): 49-72.

EMEA. (1998) Principles of providing the World Health Organization with pharmacovigilance information, CPMP/PhVWP/053/98, London: European Medicines Evaluation Agency, 19 January 1998.

EMEA. (2005) Action Plan to Further Progress the European Risk Management Strategy, EMEA/115906/2005/Final, London: European Medicines Evaluation Agency, 4 May 2005. 
FDA. (1999), Managing the Risks from Medical Product use. Creating a Risk Management Framework, Washington, DC: Food and Drug Administration.

Gaudillière, J.-P. (2009) 'New wine in old bottles? The biotechnology problem in the history of molecular biology', Studies in History and Philosophy of Science Part C: Studies in History and Philosophy of Biological and Biomedical Sciences 40(1): 20-8.

Gaudillière, J.-P. and Hess, V. (2012) Ways of Regulating Drugs in the 19th and 20th Centuries. New York: Palgrave Macmillan.

Goldman, M. (2007) 'How 'Water for All!' policy became hegemonic: The power of the World Bank and its transnational policy networks', Geoforum 38(5): $786-800$.

Görg, C. and Brand, U. (2000) 'Global environmental politics and competition between nation-states: On the regulation of biological diversity', Review of International Political Economy 7(3): 371-98.

Görg, C. and Brand, U. (2006) 'Contested regimes in the international political economy: Global regulation of genetic resources and the internationalization of the state', Global Environmental Politics 6(4): 101-23.

Harmes, A. (2006) 'Neoliberalism and multilevel governance', Review of International Political Economy 13(5): 725-49.

Hauray, B. (2006) L'Europe du Médicament: Politique, Expertise, Intérêts Privés, Paris: Presses de Sciences Po.

Hauray, B. and Urfalino, P. (2009) 'Mutual transformation and the development of European policy spaces the case of medicines licensing', Journal of European Public Policy 16(3): 431-49.

Helfer, L. R. (2004). 'Regime shifting: The TRIPS agreement and new dynamics of international intellectual property law-making', Yale Journal of International Law 29(1): 1-83.

Helfer, L. R. (2009) 'Regime shifting in the international intellectual property system', Perspectives on Politics 7(1): 39-44.

Hood, C. et al. (2001) The Government of Risk: Understanding Risk Regulation Regimes, Oxford: Oxford University Press.

Inman, B. (1993) '30 Years in postmarketing surveillance a personal perspective', Pharmacoepidemiology and Drug Safety 2(4-5): 239-58.

Kleinman, D. L. and Kinchy, A. J. (2007) 'Against the neoliberal steamroller? the biosafety protocol and the social regulation of agricultural biotechnologies', Agriculture and Human Values 24(2): 195-206.

Laing, R. et al. (2003) '25 Years of the WHO essential medicines lists: Progress and challenges', The Lancet 361(9370): 1723-9.

Lall, R. (2012) 'From failure to failure: The politics of international banking regulation', Review of International Political Economy 19(4): 609-38.

Leiper, J. M. and Lawson, D. H. (1985) 'Why do doctors not report adverse drug reactions?', The Netherlands Journal of Medicine 28(12): 546-50.

Levi-Faur, D. (2005) 'The global diffusion of regulatory capitalism', Annals of the American Academy of Political and Social Science 598: 12-32.

Mattli, W. and Woods, N. (2009) 'In whose benefit? explaining regulatory change in global politics', in W. Mattli and N. Woods (eds) The Politics of Global Regulation, Cambridge: Cambridge University Press, pp. 1-43.

Pattberg, P. (2005) 'The institutionalization of private governance: How business and nonprofit organizations agree on transnational rules', Governance 18(4): $589-610$.

Raustiala, K. and Victor, D. G. (2004) 'The regime complex for plant genetic resources', International Organization 58(2): 277-309. 
Reid, J. (2013) 'Interrogating the Neoliberal Biopolitics of the Sustainable Development-Resilience Nexus', International Political Sociology 7(4): 353-67.

Ruggie, J. G. (1998) 'Globalization and the Embedded Liberalism Compromise: The End of an Era?', in W. Streeck (ed.) Internationale Wirtschaft, Nationale Demokratie: Herausforderungen Fur Die Demokratietheorie, Frankfurt: Campus, pp. 79-98.

Tubert, P. et al. (1992) 'Power and weakness of spontaneous reporting: a probabilistic approach', Journal of Clinical Epidemiology 45(3): 283-6.

Venulet, M. J. and Helling-Borda, M. (2010) 'WHO's international drug monitoring-the formative years, 1968-1975', Drug Safety 33(7): e1-e23.

Vogel, D. (1998) 'The globalization of pharmaceutical regulation', Governance 11(1): 1-22.

Vogel, D. (2008) 'Private global business regulation', Annual Review of Political Science 11: 261-82.

WHO (2002) The Importance of Pharmacovigilance Safety Monitoring of Medicinal Products, Geneva: WHO.

Zelli, F. et al. (2013) 'Institutional interactions at the crossroads of trade and environment: The dominance of liberal environmentalism?', Global Governance 19(1): 105-18. 